NBFR - TRT IMDARY

NBER WORKING PAPER SERIES

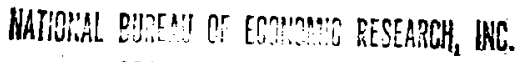
204 Jina sing E.W.

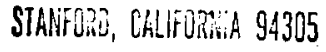

\title{
INFLATION AND THE CHOICE OF ASSET LIFE
}

\author{
Alan J. Auerbach \\ NBER and Harvard University
}

Working Paper No. 253

NATIONAL BUREAU OF ECONOMIC RESEARCH

1050 Massachusetts Avenue

Cambridge MA 02138 
Inflation and the Choice of Asset Life

SUMMARY

Given the current corporate tax structure in the U.S., inflation may have an important impact on the production decisions of firms, notably the choice of capital durability.

This paper presents a model of competitive behavior in which firms may choose the durability of their capital goods. We find that in the presence of inflation, the taxation of corporate profits may influence both the choice of asset 1 ife and the market value of equity. In particular, the failure to index depreciation allowances depresses share values and biases the choice of asset life toward greater durability.

Integrating this analysis with the traditional one-sector monetary growth model, we study the general equilibrium impact of inflation on such long run characteristics of the economy as output per capita and the real rate of return received by investors.

Alan J. Auerbach

National Bureau of Economic Research 1050 Massachusetts Avenue Cambridge, MA 02138

(617) $868-3927$ 


\section{Introduction}

One of the most important aspects of the one-sector monetary growth model developed by Tobin (1965) is the analysis of the effect of inflation on the steady-state capital intensity and real interest rate. Tobin showed that, by lowering the real return on money, inflation makes real capital more attractive as an asset and leads to capital deepening and a lower real rate of return. By including personal and corporate income taxes in the specification of this model, Feldstein (1976) has found that the failure to index these taxes for inflation may also have a substantial impact on the economy's steadystate characteristics. One aspect of the problem which has not been adequately explored is the effect of inflation on the production decisions of firms.

The current structure of the U.S. corporate income tax has the effect of greatly distorting investment decisions among various assets. The investment tax credit may be applied to purchases of certain equipment, but not structures. Even in the absence of inflation, depreciation schedules used for tax purposes do not mirror true economic depreciation. ${ }^{I}$ with the advent of inflation, this distortion is compounded by the fact that these schedules are based on the original or "historic" cost and not the replacement cost of the capital being depreciated. $^{2}$

In the next section, we present a model of competitive finm behavior when the durability of capital is subject to choice by the Eirm. A steady-state growth path will have two important characteristics when

*The author would like to thank Martin Feldstein for helpful discussions on this subject. The research reported here is part of the NBER's research program in Business Taxation and Finance. Any opions expressed are those of the author and not those of the National Bureau of Economic Research. 
there is no corporate taxation. First, firms will evaluate capital investments of differing durability using the same discount rate. Second, the market value of a firm will exactly equal the reproduction cost of the capital assets which it owns.

The results are extended in section III to the case where there is a corporate income tax. In the presence of inflation, the taxation of corporate profits may influence both the choice of asset life and the market value of corporate equity. It turns out that market value will equal reproduction cost if the tax schedule for asset depreciation corresponds to true economic depreciation, measured at replacement cost. The effective tax rate on corporate income will be independent of the choice of asset life if the depreciation schedule is a linear combination of such "replacement cost depreciation" and immediate expensing. When depreciation allowances mirror capital decay, but are not indexed for inflation, share value is depressed and the choice of asset life is biased toward greater durability,

In section $I V$, we integrate our analysis of the firn with the traditional one-sector monetary growth model. We derive in section $V$ the effect of inflation on the characteristics of the steady state. For the case in which depreciation allowances are properly indexed, an increase in the inflation rate leads to an increase in capital durability. The ability of firms to vary asset life causes greater capital deepening, and a smaller decline in the real rate of return, than occur in earlier models from an increase in inflation. Additional analytical results, supported by findings from a numerical simulation 
in Section VI, indicate that the failure to index depreciation allowances may induce a further shift to the use of more durable assets under inflationary circumstances.

II. The Choice of Asset Iife

We consider the steady state of a growing economy with one production sector, in which we assume there is perfect competition and constant returns to scale in production. Finms produce output using two factors, capital and homogenous labor. The price of new capital goods at time $t$ is, of course, equal to the price of all "other" goods, denoted $P_{t}$. The wage rate is $w_{t}$. The rate at which $p$ and $w$ inflate is denoted $\pi$. Savings by individuals may take the form of money or fim equity. The government issues money, which carries a fixed a nominal return of zero, and raises the remainder of its required revenues through lump sum taxes and the taxation of corporate income. ${ }^{3}$ The rate at which equity holders discount nominally measured flows from the firm is $r$.

Capital goods decay exponentially at a constant rate, $\delta$. However, $\delta$ is variable ex ante, and subject to choice by the firm. We assume that increases in $\delta$ increase the flow of capital services per unit of time from a urit of capital, such increases being subject to diminishing returns. This flow is represented by the function $A(\delta)\left(A^{\prime}>0\right.$, A" < 0). Gross output is defined by:

(1) $Y^{G}=H(R S, I) ; H_{R^{\prime}} H_{I^{\prime}} H_{K L}>0 ; H_{K K^{\prime}} H_{L I}<0$ 
where $\mathrm{H}$ is homogenous of degree one in its two inputs, labor, $I$, and capital services, $k s$. Let $I_{t}$ be the nominal investment at time $t$, and $\delta_{t}$ the corresponding decay rate chosen by the firm. Then the net net capital stock remaining from this investment at time $s>t$ is $\left(I_{t} / P_{t}\right) e^{-\delta_{t}(s-t)}$. Thus, total capital services at time $s$ are:

(2) $\quad k s_{s}=\delta_{-\infty}^{s} A\left(\delta_{t}\right)\left(I_{t} / p_{t}\right) e^{-\delta_{t}(s-t)} d t$.

Corporate profits are taxed at rate $\tau$, after the deduction of wages and depreciation allowances. We denote as $D(x, \delta)$ the deduction permitted per dollar of initial investment for an asset of age $x$ which decays at rate $\delta$.

In the model we are considering, with no uncertainty or market imperfections, the fim's objective is the maximization of the current wealth of shareholders through the maximization of its own present value, which is:

$$
\begin{aligned}
V= & \int_{0}^{\infty} e^{-I t} \\
& \left\{(I-\tau)\left[P_{t} Y_{t}^{G}-w_{t} I_{t}\right]-P_{t} I_{t}+\tau \int_{-\infty}^{t} I_{s} D\left(t-s, \delta \delta_{s}\right) d s\right\} d t .
\end{aligned}
$$

Differentiating $v$ with respect to $\delta_{t^{\prime}} I_{t^{\prime}}$ and $I_{t^{\prime}}$ we obtain the firstorder conditions for present value maximization; for all $t$ :

$$
\text { (4.1) } \delta_{t}^{\infty}\left[A^{\prime}\left(\delta_{t}\right)-A\left(\delta_{t}\right)(s-t)\right] H_{K}\left(K s_{s^{\prime}} L_{s}\right) e^{-\left(p+\delta_{t}\right)(s-t)} d s
$$




$$
=\frac{\partial}{\partial \delta_{t}}\left[\left(1-\tau z\left(\delta_{t}\right)\right) /(1-\tau)\right]
$$

(4.2) $\int_{t}^{\infty} A\left(\delta_{t}\right) H_{K}\left(R s_{s} I_{s}\right) e^{-\left(p+\delta_{t}\right)(s-t)} d s=\left(1-\tau z\left(\delta_{t}\right)\right) /(1-\tau)$

(4.3) $B_{L}\left(K S_{t}, I_{t}\right)=w_{t} / P_{t}$

where $\rho=r-\pi$ is the real discount rate and

$$
z(\delta)=\delta_{0}^{\infty} e^{-r s} D(s, \delta) d s
$$

is the present value of depreciation allowances for a unit of new capital which decays at rate $\delta$.

Before simplifying (4), we introduce a concept which will aid in understanding firm behavior. Let a unit of "effective capital" be that amount of capital which is needed to provide one unit of capital services per unit time. The size of a unit of effective capital is $[A(\delta)]^{-1}$, where $\delta$ is the decay rate of the capital in question. similarly, the price of a new unit at time $t$ is:

$$
p_{t}^{\star}=p_{t} / A(\delta)
$$

In a steady state, the value of $\delta$ chosen by firms will be constant over time. Thus, if we define the net capital stock available at time $t$ in output units: 
(7) $\quad k_{t}=f_{-\infty}^{t}\left(I_{s} / p_{s}\right) e^{-\delta(t-s)} d s$

then capital services at time $t$ are $K S_{t}=A(\delta) K_{t}$. Since conditions (4.1) and (4.2) must hold for all $t$, we may differentiate them with respect to $t$ to obtain conditions which also must hold. Substituting these back into the original conaitions and using (7), we rewrite the first-order conditions (4) (dropping time subscripts):

(8.1) $\frac{\partial c}{\partial \delta}=0$

(8.2) $\mathrm{E}_{\mathrm{K}}(\mathrm{A}(\delta) \mathrm{K}, I)=\mathrm{c} / \mathrm{p}$

(8.3) $H_{L}(A(\delta) K, L)=W / P$

where

$$
c_{t}=p_{t}^{*}(0+\delta)(1-\tau z) /(1-\tau)
$$

is the shadow price of capital, masured in effective units, referrec to by Jorgenson (1963) as the "user cost of capital." We may interpret the optimal steady-state production behavior of the fin, outlined in (8), as having two steps. In the first step, described by equation (8.1), fins minimize the implicit cost of capital services, c, by their choice of $\delta$. Once this is done, labor and capital services are combined to maximize profits, with their marginal revenue products being equated with their marginal costs. 4 
Swan (1970) has studied the problem of firms which perform the first of the productive steps described above, the creation of capital services through choice of $\delta$, for the special case in which $\tau=0$. In this situation, (8.1) simplifies to:

$$
\rho+\delta=-\frac{p^{\star}}{\partial p^{\star} / \partial \delta}
$$

which is precisely the condition derived by Swan.

We next discuss the firm value which results from the optimization process. Substituting (7), (8), and (9) into (3), we obtain:

(1I) $V=p_{0} K_{0}(I-\tau z)+\tau \int_{0}^{\infty} e^{-\tau t} f_{-\infty}^{0} I_{s} D(t-s) d s d t$.

Thus, the ratio of firn value to the reproduction cost of its net capital stock is ${ }^{5}$ :

(12) $q=(I-\tau z)+\left(p_{0} K_{0}\right)^{-I} \tau \int_{0}^{\infty} e^{-\tau t} \rho_{-\infty}^{0} I s D(t-s) d s d t$.

When there are no corporate taxes, $q=1$, so that the market value of a firm equals the replacement cost of its tangible assets.

III. Taxation and Depreciation

With the advent of corporate taxation, firm behavior changes due to changes is the capital rental price, $c$. If we define the firm's "implicit discount rate" to be: 
(13) $v=(0+\delta)(1-\tau z) /(1-\tau)-\delta$

then it is easily verified that fims behave exactly as they would in a world without taxation, using $v$ rather than $\rho$ as the relevant discount rate, Since investors still receive a rate of return equal to $\rho$, the effective corporate tax rate may be defined as:

$$
\theta=(v-p) / v
$$

of course, if $\tau=0$, then $v=\rho$ and $\theta=0$. When $\tau>0$, the magnitude of $\theta$ depends on the depreciation scheme followed. Further, $\theta$ may vary according to the rate of capital decay chosen.

Suppose that the actual tax laws allowed a fraction e of all capital to be expensed, ${ }^{6}$ with the remaining capital allowed true economic depreciation, measured at current replacement cost. The value of $z$ for expensed capital is one, since the full deduction is received inmediately. From a dollar of capital purchased at time $t$, the amount available at time $s$ is $\left(1 / p_{t}\right) e^{-\delta(s-t)}$. The value of such capital at current prices is found by multiplying this term by $P_{5}$. Multiplying the resulting term by $\delta$ gives the value of $D(s-t, \delta)$ for economic, replacement-cost depreciation:

$$
D_{R}(s-t, \delta)=\delta e^{-\delta(s-t)}\left(p_{s} / P_{t}\right)
$$

The present value of such allowances is:

$$
z_{R}=\delta /(0+\delta)
$$


Thus, the total value of $z$ per unit of capital would, in the case with a fraction e expensed, be:

(17) $z_{e}=e+(1-e) \delta /(p+\delta)$

Substitution into (13) gives:

(18) $v=p(1-\tau e) /(1-\tau)$.

The effective tax rate is, therefore:

(19) $\theta=\tau(1-e) /(1-\tau e)$

which is not dependent on $\delta$. The effective tax rate varies from $z e r o$, when full expensing is followed, to $\tau$, when $e=0.7$

Now, consider the case where depreciation allowances mirror true decay of capital, but are measured at original or "historic" cost. The deduction allowances are:$$
D_{E}(s-t, \delta)=\delta e^{-\delta(s-t)} .
$$

The present value of suci allowances is:

(21) $z_{B}=\delta /(\rho+\pi+\delta)$.

Substitution into (13) yields:

(22) $\nu=\rho /(1-\tau)+\pi \tau z_{E} /(1-\tau)$ 
and, from (14):

$$
\theta=\left(\tau p+\pi \tau z_{K}\right) /\left(0+\pi \tau z_{E}\right)
$$

We may observe two things. First, if $\pi>0, \theta$ is greater than $\tau$, the value of the effective tax rate when the depreciation schedules are indexed [see (19)]. This extra "tax" may be understood by viewing the stream of tax savings from depreciation deductions as coupon receipts from a nominally denominated asset. In the absence of inflation, this asset has present value $\tau z_{\mathrm{H}} /(1-\tau)$, since the tax savings are not, themselves, subject to taxation. When the price level increases by $\pi$, the real value of this asset decreases, since it is not indexed, at rate $\pi$, which involves a real cost of $\pi \tau z_{K} f(1-\tau)$, which appears on the rigrt-hand size of (22), along with the real, before-tax, cost of funds, $p /(1-\tau)$. Of equal importance is the fact that the size of this "depreciation asset" and hence its annual loss in value due to inflation, increases with $\delta$. Thus, $d \theta / d \delta>0$, and the choice of asset durability is biased toward the choice of long-lived assets with low values of $\delta$.

We now consider the effect of corporate taxation on the value of q, the ratio of a firm's market value to the reproduction cost of its capital stock.

When replacement cost econonic depreciation is allowed, the value of $q$ is: 
(24) $q_{R}=\left(I-\tau z_{R}\right)+\left(p_{0} K_{0}\right)^{-I} \tau \int_{0}^{\infty} e^{-r t} \rho_{-\infty}^{0}\left(I_{s} / p_{s}\right) p_{t} \delta e^{-\delta(t-s)} d s d t$ which, using (7), yields:

$$
q_{R}=\left(1-\tau z_{R}\right)+\left(p_{0} K_{0}\right)^{-1} \tau p_{Q} K_{Q} z_{R}=1
$$

The equality between capital reproduction cost and fin value is maintained.

When firms are permitted to expense purchases of capital immediately, $z=1$, and the second tezm on the right-hand side of (12) disappears, since no capital currently owned by the firm has any depreciation allowances remaining. Thus, $q=1-\tau$. For a scheme in which firms may expense a fraction e of new purchases, following replacement cost depreciation for the rest, the value of $q$ is:

$$
q_{e}=e(1-\tau)+(1-e)=1-\tau e
$$

When allowances are not indexed but otherwise reflect economic depreciation, $q$ drops below unity with the advent of inflation. The precise value of $q$ depends on the age structure of a unit of a fin's capital stock. The older a unit of capital is, the lower the price level at which its depreciation allowances are computed. This makes older capital less desirable than new capital, which has a price per unit of $P_{t}$ at time $t$. Thus, the average valuation per unit of firmheld capital must be lower than $P_{t}$, and will decline as the average age of the net capital stock increases. 
In a steady state, a representative firm increases its real investment at each moment in time at rate $n$, the growth of the labor force in the economy. Thus, the firm investment flows at times $t$ and $s$ are related by:

$$
\left(I_{t} / P_{t}\right)=\left(I_{s} / P_{s}\right) e^{-n(s-t)} .
$$

Therefore, the net capital stock at time $s$ is:

$$
K_{s}=f_{-\infty}^{s}\left(I_{s} / p_{s}\right) e^{-n(s-t)} e^{-\delta(s-t)} d t=\left(I_{s} / p_{s}\right) /(n+\delta) .
$$

For the case of historic cost depreciation, we may use $(20),(21)$, and (27) to express $q$ as :

$$
q_{H}=I-\tau z_{H}+\left(p_{0} K_{0}\right)^{-I} \tau f_{0}^{\infty} e^{-\tau t} \delta_{-\infty}^{0}\left(I_{0} / p_{0}\right) e^{n s} p_{s} \delta e^{-\delta(t-s)} d s d t .
$$

Equation (29) may be simplified with the aid of (28) to yield:

$$
q_{H}=\left(1-\tau z_{H}\right)+\tau z_{H}[1-\pi /(n+\delta+\pi)]=1-\tau z_{H} \pi /(n+\delta+\pi)
$$

which confirms that $q<1$, for $\pi>0$, and that $q$ decreases as $n$ decreases, since the average age of the firm's capital stock increases. Thus, even if depreciation allowances do appropriately reflect economic depreciation, the failure to index such allowances influences corporate activity in two important ways. First, the effective corporate tax rate becomes systematically related to the durability of capital used in production, with a higher rate being assessed on short- 
lived assets. Second, the market value of a representative corporation drops below the replacement value of its capital stock. These two resuits will, in turn, influence the characteristics of the steady state growth path of the economy.

IV. Steady-State Behavior

In this section, we incorporate the foregoing analysis of the firm into a neoclassical growth model. A complete presentation of the basic model may be found in solow (1970).

In a steady state, gross output may be expressed as a function of the capital stock, labor in use, and capital decay rate:

$$
Y^{G}=G(K, L, \delta)=H(A(\delta) K, I)
$$

The corresponding value of net output is $Y^{G}$ less capital decay:

$$
Y^{N}=F(K, L, \delta)=G(K, L, \delta)-\delta K .
$$

Since the functions $G$ and $F$ are homogenous of degree one in $K$ and $I$, we may divide by I to write each in intensive form:

$$
y^{G}=g(k, \delta)=h(A(\delta) k)
$$

$$
y^{N}=f(k, \delta)=g(k, \delta)-\delta k
$$

Using (13) and (34), we may rewrite the first-order conditions for firm optimization, (8), more conveniently as: 
$(35.1) f_{\delta}=k \frac{\partial v}{\partial \delta}$

$(35.2) \quad E_{k}=v$

$(35,3) \in=v k+\frac{w}{p}$.

We assume that the economy has a population growing at rate $n$, with labor supplied inelastically, ${ }^{8}$ and that government expenditures comprise a fixed fraction; $\gamma$, of net output. These expenditures are finarced, in part, by expanding the money supply at a nominal growth rate, g. The rest of the required revenue is raised through taxes, including the corporate income tax. Letting m and T represent real money balances and taxes per capita, the government budget constraint is:

(36) $\gamma f(k, \delta)=g m+T$.

Disposable income is defined to be gross income, less taxes and capital losses in the value of money and equity holdings. Money balances decline in value at the rate of inflation, so that the per capita loss on money balances is:

(37) $\Delta_{m}=\pi m$.

Per capita losses in the value of equity could be calculated directly. However, there is a much simpler way. Since the net capital stock must grow at rate $n$, gross investment must satisfy: 


$$
I_{t}=(n+\delta) R_{t}
$$

After accounting for new investment, the real value of equity in the economy must also grow at rate $n$ :

$$
\left(v_{t} / p_{t}\right)=n\left(v_{t} / p_{t}\right)=n q K_{t}
$$

Since new investments raise firm value by the exact amount of their cost, the drop in value of current equity holdings, in per capita terms, must therefore be:

$$
\begin{aligned}
& \Delta_{k}=(n+\delta) k-n q k=[\delta+(1-q) n] k \\
& \text { Disposable income as defined above is: }
\end{aligned}
$$

(41) $y^{d}=g(k, \delta)-T-\Delta_{m}-\Delta_{k}$.

In a steady state, real money balances must grow at rate $n$. Thus, $g-\pi=n$, and we may substitute $(36),(37)$, and (40) into (41) to obtain:

$$
y^{d}=(1-\gamma) f(k, \delta)+n m-n(1-q) k
$$

Note that when there are no corporate taxes, or when depreciation allowances mirror true capital decay valued at current prices, the last term in (42) drops out.

At any time, real private wealth, representing equity and money balances, must grow at rate $n$. Let $\sigma$ be the fraction of disposable 
income saved, that is, allotted to increases in wealth. Then:

(43) $\sigma y^{d}=n(m+q k)$

The fraction of their portfolios which individuals seek to hold in real money balances is denoted $\ell /(1-\ell)$. Therefore:

(44) In = lqk.

From $(42)-(44)$, we get:

$$
f(k, \delta) / k=\left[\frac{n(1+l)(1-\sigma)}{\sigma(1-\gamma)}\right] q+\left(\frac{n}{1-\gamma}\right)=a q+b .
$$

In general, $\sigma$ may be sensitive to the real rate of return, $\rho$, and $l$ would be expected to depend negatively on both $\rho$ and $\pi$. Thus, a is a function of $\rho$ and $\pi$. By the assumptions stated above, b is fixed.

Since all gross output is either invested, consumed by the government, or consumed by the private sector, total private and public consumption per capita is:

$$
C=g(k, \delta)-(n+\delta) k=f(k, \delta)-\Omega k .
$$

For any particular assumption about the structure of depreciation allowances, equations (12), (13), (35), (45), and (46) comprise a system of seven equations in eight unknowns: $k, \rho, v, w / p, \delta, q, c$, and $\pi$. By dropping (35.3) and substituting (13) into (35.1) and (35.2), we obtain a system in $k, \rho, \delta, q, c$, and $\pi$. By differentiating this system with respect to $\pi$, we may assess the impact that a change in the 
rate of inflation has on the steady-state values of the other five unknown variables.

V. The Effect of Changes in $\pi$

We first consider the case in which the depreciation schedule is a combination of expensing and replacement cost economic depreciation. Onder this regime, the system defined at the end of the previous section reduces to:

(47.1) $E_{k}=\rho(1-\tau e) /(1-\tau)$

(47.2) $E_{\delta}=0$

(47.3) $f / k=a q+b$

$(47.4) q=1-\tau e$

(47.5) $C=f-n k$.

Totally differentiating this system with respect to $\pi$, we obtain:

(48.1) $\frac{d k}{d \pi}=a_{\pi} \cdot \Delta_{1}^{-1}$

(48.2) $\frac{d o}{d \pi}=\Delta_{0} \cdot \frac{d k}{d \pi}$

(48.3) $\frac{d \delta}{d \pi}=-\frac{f_{\delta k}}{f_{\delta \delta}} \cdot \frac{d k}{d \pi}$ 
(48.4) $\frac{d C}{d \pi}=\left(f_{k}-n\right) \frac{d k}{d \pi}$

(48.5) $\frac{d g}{d \pi}=0$

where :

$$
\Delta_{0}=\frac{(1-\tau)}{q} \cdot\left(\frac{f_{k k} f_{\delta \delta}-f_{k \delta}^{2}}{f_{\delta \delta}}\right)
$$

(49) and

$$
\Delta_{I}=\frac{k f_{k}-f}{q k^{2}}-a_{p} \Delta_{0} .
$$

The first thing to notice about (48) is that if the liquidity preference function, 2 (and hence a), is not dependent on $\pi$, then the system is completely insulated from the rate of inflation. In general, as long as $\ell_{\pi} \leq 0$ and $\ell_{p} \leq 0 \leq \sigma_{\rho}, a_{\pi}$ and $a_{p}$ are both less than or equal to zero.

By the definition of net output, we have:

$$
\begin{aligned}
& \text { (50.1) } f_{k k}=h^{\prime \prime}{ }^{2} \\
& (50.2) f_{\delta \delta}=h^{\prime \prime}\left(k A^{\prime}\right)^{2}+h^{\prime} k A^{\prime \prime} \\
& \text { (50.3) } f_{\delta k}=h^{\prime \prime A A^{\prime} k}+f_{\delta / k} \text {. }
\end{aligned}
$$


In the present case, $f_{\delta}=0$, so that $f_{k k^{\prime}} f_{\delta \delta^{\prime}}$ and $f_{\delta k}$ are all negative and

$$
f_{k k} f_{\delta \delta}-f_{k \delta}^{2}=h^{\prime \prime} h^{-} k A^{2} A "
$$

is positive. Thus, $\Delta_{0}<0$. Since the term $\left(k f^{\prime}-f\right)$ equals $\left[(A k) h^{\prime}-h\right]$, it is negative by the assumption that $h$ is convex. It follows that $\Delta_{1}<0$. Therefore, $d k / d \pi>0, d 0 / d \pi<0$, and $d \delta / d \pi<0$. Total consumption, $C$, increases with the increase in the capital-labor ratio if $E_{k}>n$, which is the condition that holds when $k$ is below the value which would yield a "golden rule" growth path on which $C$ would be at a maximum. 9

As in earlier models in which the choice of asset life was not considered, inflation induces a desire on the part of individuals to shift their portfolio holdings from money to equity, and this leads to an increase in the capital-labor ratio and a decline in the real rate of return. Here, however, the capital deepening is accompanied by a shift to the use of more durable capital goods. As $\rho$ declines, the user cost of capital [see (9)] declines proportionally more for capital with small values of s-durable capital. Fims alter their production behavior to take advantage of this tilting of relative prices.

The ability of finms to choose $\delta$, with the resulting increase in asset durability, leads to a greater increase in $k$, and a smaller decrease in $p$, than would oceur if $\delta$ were fixed. To demonstrate this, 
we first observe that if $\delta$ were fixed, then condition (47.2) would no longer hold, and would be replaced by the equation $\delta=\bar{\delta}$. Differentiating the new system with respect to $\pi$, we obtain:

(52.1) $\left.\frac{d k}{d \pi}\right|_{\delta}=a_{\pi}\left[\frac{k f_{k}-f}{q k^{2}}-a_{0} \frac{(1-\tau)}{q} f_{k k k}\right]^{-1}$

(52.2) $\left.\frac{d 0}{d \pi}\right|_{\delta}=\frac{(1-\tau)}{q} f_{k k} \cdot \frac{d k}{d \pi}$

so that $\Delta_{0}$ has been replaced by $E_{k k}$. It is easy to show that $\frac{d k}{d \pi}>$ $\left.\frac{d k}{d \pi}\right|_{\delta}$ and $\frac{d \rho}{d \pi}>\left.\frac{d \rho}{d \pi}\right|_{\delta}$.

We now consider the case in which depreciation allowances follow actual economic depreciation but are not indexed. The relevant system of equations is:

(53.1) $f_{k}=0 /(1-\tau)+\tau \pi z_{H} /(1-\tau)$

(53.2) $f_{\delta}=k \pi\left(\frac{\tau}{1-\tau}\right)(p+\pi) /(0+\pi+\delta)^{2}$

(53.3) $f / k=a q+b$

(53.4) $q=1-\tau \pi z_{H} /(n+\delta+\pi)$

(53.5) $C=f-n k$.

It is difficult to determine without ambiguity the effects of an increase in $\pi$ beginning at positive rates of inflation. For this pur- 
pose, we present a numerical simulation in the next section. We consider analytically the special case of a change in $\pi$ starting at $\pi=0$. When $\pi=0$, the steady-state described by (53) is identical to that described by (47) when economic depreciation is followed $(e=0)$, so that we may assess the additional inflationary impact coming from the failure to index by comparing results derived from the two systems. Totally differentiating (53), we obtain:

(54.1) $\frac{d k}{d \pi}=\left[a_{\pi}-\tau 2 \Delta_{4}\right] \Delta_{1}^{-1}$

(54.2) $\frac{d p}{d \pi}=\Delta_{0} \frac{d k}{d \pi}-\tau z \Delta_{3}$

(54.3) $\frac{d \delta}{d \pi}=-\frac{E_{\delta k}}{E_{\delta \delta}} \cdot \frac{d k}{d \pi}+k\left(\frac{\tau}{1-\tau}\right) \frac{\rho}{(\rho+\delta)^{2}} \cdot \frac{1}{f_{\delta \delta}}$

(54.4) $\frac{d C}{d \pi}=\left(f_{k}-n\right) \frac{d k}{d \pi}$

(54.5) $\frac{d g}{d \pi}=-\frac{\tau z}{n+\delta}$

where $\Delta_{0}$ and $\Delta_{1}$ are as defined in (49) and:

$$
\Delta_{3}=1-\frac{\rho k}{\delta(p+\delta)} \cdot \frac{E_{k \delta}}{E_{\delta \delta}}
$$

(55) and 


$$
\Delta_{4}=\frac{a}{n+\delta}+a_{\rho} \Delta_{3}
$$

As discussed in Section III, the onset of inflation causes $q$ to drop below unity because older units of capital have depreciation allowances which are smaller, in real terms, than those given for new capital. Thus the average market value of the capital stock must be lower than if it were all new capital, or if depreciation allowances were indexed.

The remainder of the results depend on the signs of $\Delta_{3}$ and $\Delta_{4}$. Clearly, $\Delta_{3}$ is less than or equal to unity, and may be negative. However, without knowing more about the production function, there is little more we can say. Using the definition of $a$, and the fact that $\Delta_{3} \leq 1$, it follows that $\Delta_{4}$ must be positive if:

$$
n_{\sigma \rho} /(I-\sigma)-\ell n_{\ell \rho} /(I+\ell)<\rho /(n+\delta)
$$

where $n_{\sigma \rho}$ and $n_{\ell \rho}$ are the elasticities of $\sigma$ and $l$ with respect to $\mathrm{o}$. Since $\ell /(1+\ell)$ will be quite small relative to unity (see note 10 ), condition (56) will hold uniess the interest elasticity of savings is exceptionally high. For example, if we ignore the second term on the left-hand side of $(56)$, and set $\sigma=0.1, \rho=0.06, \mathrm{n}=0.02$, and $\delta=$ 0.1 , the base values used in the following section's simulation, then (56) will hold as long as $\eta_{\sigma \rho}<0.45$, a value which is higher than any empirical estimates of $\eta_{\sigma \rho}$ and much higher than most. 
Therefore, assuming $\Delta_{4}>0$, the failure to index depreciation allowances leads iritially to greater capital deepening resulting from inflation. This effect is due in part to the drop in $g$. Since the capital stock is "cheaper," the same amount of savings buys more of it. It is even more certain that the lack of replacement cost depreciation leads to a greater shift to long-lived assets. Not only will the increase likely to occur in $d k / d \pi$ lead to this, but so will the heavier effective taxation of short-lived assets, which introduces a second term on the right-hand side of (54.3). Since $\Delta_{3}$ is of ambiguous sign, we cannot be sure of the additional impact on do/dr.

We may briefly summarize the result of this section. If the demand for money is unresponsive to the rate of inflation, then proper indexing of depreciation allowances completely insulates the economy from inflation. When liquidity preference does depend on $\pi$, then $d \delta / d \pi<0$. As in previous analyses, $d k / d \pi$ is positive and $d 0 / d \pi$ negative. Eowever, the increase in $k$ is larger, and the decrease in $\rho$ smaller, than would be the case were the asset durability fixed.

When depreciation allowances are not indexed, the onset of inflation will likely lead to even more capital deepening, and a greater shift to more durable capital, both because of the added increase in $d k / d \pi$, and because the "inflation tax" falls more heavily on shortlived assets. It is not clear whether these results will still hold at high levels of inflation. We therefore proceed to a numerical simulation. 
VI. As Example

Let gross output be governed by a modified Cobb-Douglas function:

$$
g(k, \delta)=\theta k^{\alpha}{ }^{\beta}
$$

In our earlier terminology, $A(\delta)=\delta^{(B / a)}$. The equilibrium conditions (53) become:

(58.1) $\alpha \mathrm{ek}^{\alpha-1} \delta$ $\beta=\rho /(1-\tau)+\pi\left(\frac{\tau}{1-\tau}\right) \delta /(\rho+\pi+\delta)$

(58.2) $B \theta_{k}^{\alpha-1} \delta^{\beta-1}-1=\pi\left(\frac{\tau}{1-\tau}\right)(p+\pi) /(0+\pi+\delta)^{2}$

(58.3) $\theta k^{\alpha-1} \delta^{\beta}-\delta=a q+b$

(58.4) $q=1-\pi \tau \delta /[(p+\delta+\pi)(n+\delta+\pi)]$.

For simplicity, we consider the case in which a is fixed. Note that a is the gross capital share and will be larger than the share of capital in net production.

Reasonable values for the U.S. economy for the real growth rate, $n$, and the rate of corporate taxation, $\tau$, are 0.02 and $0.4 \mathrm{r}$ respectively. Osing values for $\gamma$ and $\sigma$ of $1 / 3$ and 0.1 , and assuming $l$ to be small relative to unity, ${ }^{10}$ we may use (45) to calculate a and b, arriving at 0.27 and 0.03 , respectively. We choose values for the production parameters $\theta, \alpha$, and $\beta$ which, at $\pi=0$, yield acceptable results for $\delta$, the rate of capital decay, $g$, per capita output, and $f_{k}$, 
the net marginal product of capital. Christensen and Jorgenson (1969) have estimated $\delta$ for the period 1929-1967 in the U.S. Their estimates were 0.056 for non-residential structures and 0.138 for producers' durables. We therefore choose 0.10 as the value for $\delta$ at $\pi=0$. We also set $f_{k}$ equal to 0.10 , a value roughly in line with recent estimates by Feldstein and Sumers (1977). We set per capita output at 10,000 dollars. The resulting values of the production parameters are:

$$
\theta=112.47
$$

$\alpha=0.50$

$B=0.25$.

Table 1 presents simulation results for steady-state inflation values ranging between 0 and 0.2 . Since capital decays exponentially, we include half-life as a measure of capital durability. Because $a_{\pi}=0$ in this example, proper indexing means that $\pi$ does not influence the system. Thus, the results in Table 1 for $\pi=0$ correspond to those for all values of $\pi$ for the case in which replacement cost depreciation is allowed.

For low values of $\pi$, the results corroborate our previous findings: $q$ declines, $k$ increases, and $\delta$ declines. Because of the increase in $k, C$ increases. The net marginal product of capital, $f_{k}{ }^{\prime}$ is virtually unchanged, but $\rho$ declines shapply because of the increase in $\theta$ due to the "inflation tax." 
TABIE 1

SIMULATION RESULTS

\begin{tabular}{ccccccccc}
\hline \hline$\pi$ & $\mathrm{q}$ & $\delta$ & $\begin{array}{c}\text { half } \\
\text { life }\end{array}$ & $\rho$ & $f_{k}$ & $k$ & $g$ & $c$ \\
\hline 0.00 & 1.000 & 0.100 & 6.93 & 0.060 & 0.100 & 25,000 & 10,000 & 7,000 \\
0.05 & 0.941 & 0.084 & 8.28 & 0.051 & 0.100 & 27,054 & 9,950 & 7,145 \\
0.10 & 0.932 & 0.074 & 9.35 & 0.049 & 0.104 & 27,230 & 9,683 & 7,121 \\
0.15 & 0.935 & 0.069 & 10.09 & 0.049 & 0.107 & 26,872 & 9,439 & 7,055 \\
0.20 & 0.942 & 0.065 & 10.60 & 0.049 & 0.109 & 26,461 & 9,252 & 6,992 \\
\hline
\end{tabular}

We can see that, once inflation reaches 10 percent, additional increases in $\pi$ may not have the same effects: In particular, $q$ begins to rise again and $k$ falls, along with $c$. The marginal product of capital increases, so that $f$ ceases to decline. However, the increase in capital durability continues, with asset life increasing an adaitional 13.4 percent between inflation rates of 10 and 20 percent.

One should be hesitant to draw firm conclusions from this simple example. However, it does illustrate the impact that the failure to index depreciation allowances can have on the choice of asset life, as well as other relevant economic variables.

VII. Conclusion

In this paper, we have introduced the choice of asset life into the neoclassical monetary growth framework, and have explored how this choice may be influenced by the structure of depreciation allowances, 
particularly the fact that such allowances are generally not indexed to account for inflation. Our results, summarized in the introduction, should serve to emphasize the importance of this question. 
Notes

1. See Samuelson (1964) for a discussion of tax deductibility and economic depreciation.

2. Tideman and Tucker (1976) provide a detailed analysis on this subject.

3. We thus do not consider the corporate financing decision between debt and equity, and the interaction of corporate and personal capital income taxes on this decision, under inflationary conditions. Such a study is quite complex in itself, and well beyond the scope of this paper. A treatment of this question can be found in Feldstein, Green, and Sheshinski (1978).

4. Since we have assumed constant returns to scale in production, equation (8) defines only the optinal ratio between capital services and labor, and not the level of each. Further, (8.2) and (8.3) may be solved independently for this ratio, and must give the same value in equilibrium.

5. Note that $q$ differs from the marginal increase in firm value resulting from an additional dollar of investment. It is easily verified that, at an optimum, the latter must always equal unity. In the language of Tobin and Brainard (1977), we are measuring the average and not the marginal value of "q."

6. That is, deducted as a current expense upon purchase. 
7. Similar results have been derived by King (1975) and Harberger (1976) for the case in which $\pi=0$.

8. When Earrod-neutral technical change is present, $n$ is interpreted as the population growth rate plus the rate of innovation.

9. See Phelps (1961).

10. Feldstein (1976) has estimated the ratio in the 0.S. of outside money to private wealth to be about $1 / 40$. 


\section{References}

Aaron, H.J, editor, 1976, Inflation and the Income Tax, (Brookings Institution, Washington, D.C.).

Christensen, L.R. and D.W. Jorgenson, 1969, "The Measurement of O.S. Real Capital Input, 1929-1967," Review of Income and Wealth, December; 293-320.

Feldstein, M.S., 1976, "Inflation, Taxes, and the Rate of Interest: A Theoretical Analysis," American Economic Review, December; 809820.

Feldstein, M.S., J. Green, and E. Sheshinski, 1978, "Inflation and Taxes in a Growing Economy with Debt and Equity Finance," Journal of Political Economy, forthcoming.

Feldstein, M.S. and I. Sumers, 1977, "Is the Rate of Profit Falling?" Brookings Papers on Economic Activity, 1, 211-228.

Hall, R.E. and D.W. Jorgenson, 1971, "Application of the Theory of Optimum Capital Accumulation," in G. Fromm, editor, Tax Incentives and Capital Spending, (Brookings Institution, Washington, D.C.).

Harberger, A.C., 1976, "Tax Incentives to Investment in Bolivia," mimeographed.

Jorgenson, D.W., 1963, "Capital Theory and Investment Behavior," American Economic Review, May; 247-259.

King, M.A., 1975, "Taxation, Corporate Financial Policy, and the Cost of Capital: A Comment," Journal of Public Economics, August; 271-279. 
Phelps, E.S., 1961, "The Golden Rule of Accumulation: A Fable for Growthmen," American Economic Review, September; 638-643. Samuelson, P.A., 1964, "Tax Deductibility of Economic Depreciation to Insure Invariant Valuations," Journal of Political Economy, December; 604-606.

Sandmo, A., 1974, "Investment Incentives and the Corporate Income Tax," Journal of Political Economy, March; 287-302.

Solow, R.M., 1970, Growth Theory: An Exposition, (Oxford University Press: Oxford).

Swan, P.L., 1970, "Durability of Consumption Goods," American Economic Review, December; 884-894.

Tideman, T.N. and D.P. Tucker, 1976, "The Tax Treatment of Business Profits under Inflationary Conditions," in H.J. Aaron, editor, Inflation and the Income Tax.

Tobin, J., 1965, "Money and Economic Growth," Econometrica, October; $671-684$.

Tobin, J. and W.C. Brainard, 1977, "Asset Markets and the Cost of Capital," Cowles Foundation Paper \$440. 